\title{
Components of Urinary Crystallites in 56 Cases of Patients with Magnesium Ammonium Phosphate Stones
}

\author{
Qiong-Zhi Gan \\ Institute of Biomineralization and Lithiasis Research \\ Jinan University \\ Guangzhou 510632 \\ Email: zwenxiaoling@163.com
}

\author{
Jian-Ming Ouyang* \\ Institute of Biomineralization and Lithiasis Research \\ Jinan University \\ Guangzhou 510632 \\ Email: toyjm@jnu.edu.cn
}

\begin{abstract}
Purpose] The formation of kidney stones related closely to the properties of urinary nanocrystallites. This study aimed to investigate the components of urinary crystallites in 56 cases of patients with magnesium ammonium phosphate (MAP) stones compared with the components of stones. [Methods] X-ray diffraction (XRD), Fourier-transform infrared (FT-IR) spectrometer, and fast Fourier transformation (FFT) of high-resolution transmission electron microscopy (HRTEM) were performed. [Results] The main components of MAP stones were found to be MAP hexahydrate $\left(\mathrm{MAP} \cdot 6 \mathrm{H}_{2} \mathrm{O}\right)$ and a small amount of magnesium hydrogen phosphate trihydrate (newberyite, $\mathrm{MgHPO}_{4} \cdot 3 \mathrm{H}_{2} \mathrm{O}$ ), calcium oxalate monohydrate (COM), calcium phosphate (CaP), and hydroxyapatite (HAP), whereas the main components of urinary crystallites in patients with MAP stones were newberyite, MAP monohydrate $\left(\mathrm{MAP} \cdot \mathrm{H}_{2} \mathrm{O}\right)$, and small amounts of $\mathrm{MAP} \cdot 6 \mathrm{H}_{2} \mathrm{O}$, COM, and CaP. [Conclusions] The formation of MAP stones was closely related to high concentration of MAP and newberyite crystals in urine. The formation mechanism and the influential factors of MAP stones were discussed on the basis of the components of urinary crystallites.
\end{abstract}

Key words: Nanocrystallite; struvite; HRTEM; magnesium ammonium phosphate

\section{INTRODUCTION}

Urinary stones can be divided into acidic, neutral, and alkaline stones based on their chemical properties. Acidic stones mainly were uric acid (UA) and cystine with an incidence of $15 \%$ and $1 \%$ respectively; neutral stones mainly were calcium oxalate $(\mathrm{CaOx})$ with an incidence of $55 \%$; alkaline stones mainly were magnesium ammonium phosphate (MAP) with an incidence of $15 \%$ [1].

Urinary stone formation involves the nucleation, growth, aggregation, and adhesion of urinary crystallites [2-4]. Therefore, the conditions of urinary crystal formation are closely related to those of urolithiasis $[5,6]$. On one hand, the disappearance of specific types of urinary crystallites in urine (e.g., cystine and struvite) demonstrates a recurring trend of reduction in stone formation. On the other hand, the continuous or new appearance of these urinary crystals in urine indicates a continuous risk of stone formation or lithiasis relapse.

Daudon [7] detected crystallites in morning urine samples, along with full 24-hour urine biochemical characteristics, in 181 patients with idiopathic calcium nephrolithiasis; in these cases, urinary crystallites were detected at a higher rate in the morning urine of 72 cases of patients than in full 24-hour urine. The main component of MAP stones is MAP hexahydrate $\left(\mathrm{MAP} \cdot 6 \mathrm{H}_{2} \mathrm{O}\right)$; urinary crystallites mainly contain $\mathrm{MAP} \cdot 6 \mathrm{H}_{2} \mathrm{O}$ and MAP monohydrate $\left(\mathrm{MAP} \cdot \mathrm{H}_{2} \mathrm{O}\right)$ [8].

High-resolution transmission electron microscopy (HRTEM) combined with selected area electron diffraction (SAED) has been performed to detect the morphological characteristics, component, and crystal structure of samples. Some biominerals, such as $\mathrm{CaP}$ and calcium carbonate, and their crystallization kinetics have also been investigated using this method. However, studies on urinary nanocrystallites using this method have not been reported.

Detecting crystallite components can help predict renal stone formation and even the formation of different types of stones, thereby providing information on appropriate remedies and personalized treatments.

Based on this, the components of urinary crystallites in 56 cases of patients with MAP stones were investigated and compared with the components of stones.

\section{MATERIALS AND METHODS}

\section{A. Reagents and instruments}

Absolute ethanol was of analytical purity. Glass vessels were cleaned with distilled water.

$\mathrm{X}$-ray diffraction (XRD) results were recorded using a D/max 2400 X-ray diffractometer (Rigaku, Tokyo, Japan) with Ni-filtered $\mathrm{Cu} \mathrm{Ka}$ radiation $\left(\mathrm{k}=1.54 \mathrm{~A}^{\circ}\right)$ at a scanning rate of $2^{\circ} \min ^{-1}(40 \mathrm{kV}, 30 \mathrm{~mA})$. The divergence and scattering slit was $1^{\circ}$ for the range of $5^{\circ}<2 \theta<60^{\circ}$. A Nicolet 6700 Fourier-transform infrared (FT-IR) spectrometer (Nicolet Company, USA) was also used. TEM was conducted on a HRTEM (JOEL 2100F) with a maximum acceleration voltage of $200 \mathrm{kV}$ and lattice resolution of 0.19 . To determine the component of urinary nanocrystallites, we performed fast Fourier transformation (FFT) of HRTEM. FFT analysis in the Digital Micrograph software was also conducted to obtain the patterns.

\section{B. Collection and component detection of stones}

56 cases of MAP stones were collected from patients with calculi after surgery, disinfected with $75 \%$ alcohol, cleared with distilled water, and placed in a dust-free 
incubator at $45{ }^{\circ} \mathrm{C}$ to dry. The urinary stones were then ground to powder by an agate mortar for XRD characterization. It was showed that the main components of these nine stones were MAP.

\section{Collection, treatment, and XRD and FT-IR detection of urinary crystallites}

Urine samples were collected from kidney stone patients admitted to the Lithotripsy Center of the First Affiliated Hospital of Jinan University, Guangzhou, China. $\mathrm{pH}$ was detected and $2 \% \mathrm{NaN}_{3}$ solution $(10 \mathrm{~mL} / \mathrm{L}$ urine sample) was added to the urine samples as antiseptic. Approximately $30 \mathrm{~mL}$ of urine was then centrifuged at $4000 \mathrm{r} / \mathrm{m}$ for $15 \mathrm{~min}$, and the supernatant was removed. The residual was washed and allowed to stand for $3 \mathrm{~min}$; the supernatant was then removed. This process was repeated twice. The residual was placed on clean glass slides by using a dropper. The slides were dried in a vacuum desiccator for further XRD and FT-IR characterization.

\section{HRTEM detection of urinary nanocrystallites}

In addition to XRD and FT-IR characterization, FFT of HRTEM was performed to investigate the components found in urinary crystallites. The urine sample was initially subjected to ultrasound treatment for $5 \mathrm{~min}$. Approximately $5 \mu \mathrm{L}$ of urine was submerged in a copper mesh by using a microsyringe; urine was preliminarily dried using an absorbent paper from the back of the mesh to remove the water content of urine. After treatment was performed, most of the soluble salts (such as $\mathrm{NaCl}$ and urea) in urine were removed by the filter paper. The mesh was then stored in a desiccator for $2 \mathrm{~d}$ before HRTEM and FFT analyses were performed.

\section{RESULTS}

\section{A. XRD and FT-IR analysis of MAP stones}

Stones with a single component occur less often because urinary stone formation is complex. Therefore, a urinary stone is considered pure when $90 \%$ of its content is a single component. By contrast, a urinary stone containing $<60 \%$ of a single component is considered mixed urinary stone. In this study, urinary stones in all of the 56 cases mainly contained $>90 \%$ of MAP.

Fig. 1 shows XRD and FT-IR spectra of stones in six representative patients with MAP stones. In XRD spectra (Figs. 1a1-1a6), we detected the diffraction peaks at $\mathrm{d}=5.91,5.60,5.38,4.26,4.14,3.47,3.29,2.96,2.78,2.69$, 2.35 and $1.96 \AA$, which were assigned to (110), (020), (011), (111), (021), (200), (130), (012), (040), (022), (231) and (103) planes of MAP $6 \mathrm{H}_{2} \mathrm{O}$, respectively $[9,10]$. We also detected the peaks at $\mathrm{d}=4.54,3.46,1.80,1.75,1.68$, and $1.58 \AA$, which were assigned to (102), (221), (144), (334), (610) and (206) planes of $\mathrm{MgHPO}_{4} \cdot 3 \mathrm{H}_{2} \mathrm{O}$, respectively; and at $\mathrm{d}=2.52,2.16$ and $1.89 \AA$, which were assigned to (2210), (3012) and (233) planes of CaP; and at $\mathrm{d}=3.65,2.97,2.35,1.98 \AA$, which were assigned to $(020)$, ( $\overline{2} 02)$, (130), ( $\overline{3} 03)$ planes of COM. The contents of $\mathrm{COM}$ and $\mathrm{CaP}$ were less since the peaks assigned to them were much weak.

In FT-IR spectra (Figs. 1b1-1b6), we detected the wave number of $v=3250 \mathrm{~cm}^{-1}$, which was assigned to the absorption peak of crystal water. The wave number of $v=2972 \mathrm{~cm}^{-1}$ were assigned to the absorption peak of CaP. The wave number of $v=3429,3255,2928,1650,1628$, $1434,1007,769$, and $571 \mathrm{~cm}^{-1}$ were assigned to the peaks of $\mathrm{MAP} \cdot 6 \mathrm{H}_{2} \mathrm{O}[11,12]$.

That is, the main components of MAP stones were found to be MAP $6 \mathrm{H}_{2} \mathrm{O}$ and a small amount of $\mathrm{MgHPO}_{4} \cdot 3 \mathrm{H}_{2} \mathrm{O}, \mathrm{CaP}$ and COM.
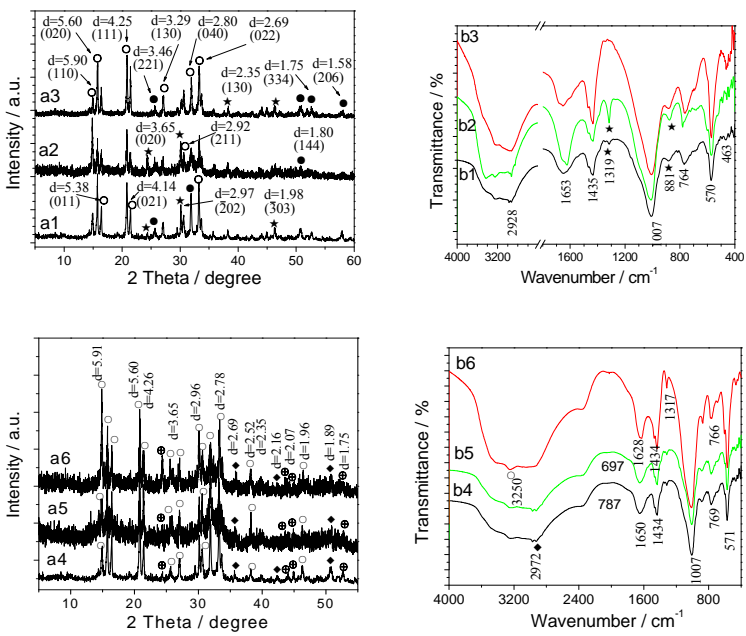

Figure 1. XRD and FT-IR spectra of six representative stones in patients with MAP stones. (a1-a6) XRD; (b1-b6) FT-IR. (a1,b1) patient $\mathrm{A} ;(\mathrm{a} 2, \mathrm{~b} 2)$ patient $\mathrm{B} ;(\mathrm{a} 3, \mathrm{~b} 3)$ patient $\mathrm{C} ;(\mathrm{a} 4, \mathrm{~b} 4)$ patient $\mathrm{D} ;(\mathrm{a} 5, \mathrm{~b} 5)$ patient E; $(\mathrm{a} 6, \mathrm{~b} 6)$ patient $\mathrm{F}$.

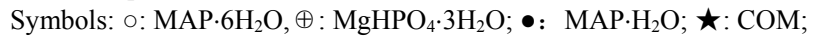
$\bullet: \mathrm{Ca}_{3}\left(\mathrm{PO}_{4}\right)_{2}$

\section{B. Component analysis of urinary crystallites in patients with MAP stones}

XRD, FT-IR, and FFT of HRTEM were performed to investigate the components of urinary crystallites of MAP stones.

Urinary crystallites were observed in 50 cases of patients among 56 cases of patients with MAP stone as the main component (Fig.2); these crystallites mainly contained MAP• $6 \mathrm{H}_{2} \mathrm{O}$, UA, newberyite, MAP• $\mathrm{H}_{2} \mathrm{O}, \mathrm{COM}$, and $\mathrm{CaP}$. They are present in combination (TABLE I ).

Although the $\mathrm{pH}$ of urine of patients with MAP stones $(6.41 \pm 0.38)$ was higher than UA and $\mathrm{CaOx}$ stones (5.23 to 6.21), UA was still detected in their urine because of higher UA concentration in patients' urine. However, the proportion of UA was relatively less in the urine of patients with MAP stones (TABLE I ) than in the urine of patients with $\mathrm{CaOx}$ stones and UA stones.

\section{1) XRD analysis}

Figs.3 showed the XRD spectra of urinary nanocrystallites from the above three patients with MAP stones. We detected the peaks at $\mathrm{d}=8.78,4.21,2.80$ and $2.50 \AA$, which were assigned to (010), (011), (200) and (031) planes of MAP $\cdot \mathrm{H}_{2} \mathrm{O}$, respectively. We also detected the peaks at $\mathrm{d}=5.08,4.66,4.44,4.12,3.63,2.19$ and 2.07 $\AA$, which were assigned to (200), (210), (102), (112), (022), (214) and (224) planes of $\mathrm{MgHPO}_{4} \cdot 3 \mathrm{H}_{2} \mathrm{O}$, and the peaks at $\mathrm{d}=6.41,4.06,3.22,1.93,1.89$ and $1.83 \AA$ were assigned to (104), (024), (214), (4010), (238) and (0210) planes of $\mathrm{CaP}$, respectively.

Compared Fig. 1 with Fig. 3, it can be seen that the stones mainly comprised $\mathrm{MAP} \cdot 6 \mathrm{H}_{2} \mathrm{O}$ and small amounts 
of $\mathrm{MgHPO}_{4} \cdot 3 \mathrm{H}_{2} \mathrm{O}, \mathrm{CaP}$ and $\mathrm{COM}$, whereas the urinary crystallites mainly comprised $\mathrm{MAP} \cdot \mathrm{H}_{2} \mathrm{O}, \mathrm{MgHPO}_{4} \cdot 3 \mathrm{H}_{2} \mathrm{O}$ and $\mathrm{CaP}$. Namely MAP $\cdot \mathrm{H}_{2} \mathrm{O}$ was not detected in stones, while $\mathrm{MAP} \cdot 6 \mathrm{H}_{2} \mathrm{O}$ was not in urinary crystallites.

TABLE I. COMPONENTS OF URINARY CRYSTALLITES IN 56 CASES OF MAP STONE PATIENTS

\begin{tabular}{|c|c|c|c|}
\hline No. & $\begin{array}{l}\text { Components of } \\
\text { urinary crystallites }\end{array}$ & Number & $\begin{array}{l}\text { Percentage } \\
/ \%\end{array}$ \\
\hline \multirow[t]{2}{*}{1} & newberyite + & 21 & 37.5 \\
\hline & $\mathrm{MAP} \cdot \mathrm{H}_{2} \mathrm{O}+\mathrm{CaP} * * * *$ & & \\
\hline 2 & $\mathrm{MAP} \cdot 6 \mathrm{H}_{2} \mathrm{O}+$ newberyite & 11 & 19.6 \\
\hline \multirow[t]{2}{*}{3} & $\mathrm{MAP} \cdot 6 \mathrm{H}_{2} \mathrm{O}+$ newberyite & 5 & 8.9 \\
\hline & $+\mathrm{MAP} \cdot \mathrm{H}_{2} \mathrm{O}+\mathrm{CaP}$ & & \\
\hline 4 & $\mathrm{MAP} \cdot \mathrm{H}_{2} \mathrm{O}+\mathrm{COM}$ & 8 & 14.3 \\
\hline \multirow[t]{2}{*}{5} & $\mathrm{MAP} \cdot 6 \mathrm{H}_{2} \mathrm{O}+\mathrm{MAP} \cdot \mathrm{H}_{2} \mathrm{O}$ & 3 & 5.4 \\
\hline & $+\mathrm{COM}+\mathrm{UA}$ & & \\
\hline 6 & $\mathrm{MAP} \cdot 6 \mathrm{H}_{2} \mathrm{O}+\mathrm{UA}+\mathrm{COM}$ & 1 & 1.8 \\
\hline 7 & $\mathrm{UA}+\mathrm{COM}$ & 1 & 1.8 \\
\hline 8 & No crystallites & 6 & 10.7 \\
\hline Total & & 56 & 100 \\
\hline
\end{tabular}

$\left[{ }^{*}\right]$ Newberyite: magnesium hydrogen phosphate trihydrate; $\mathrm{MAP} \cdot 6 \mathrm{H}_{2} \mathrm{O}$ : magnesium ammonium phosphate hexahydrate; $\mathrm{MAP} \cdot \mathrm{H}_{2} \mathrm{O}$ : magnesium ammonium phosphate monohydrate; $\mathrm{CaP}$ : calcium phosphate; $\mathrm{COM}$ : calcium oxalate monohydrate; UA: uric acid.

$\left[{ }^{* *}\right]$ The components of urinary crystallites were sorted in terms of their contents (from high to low)

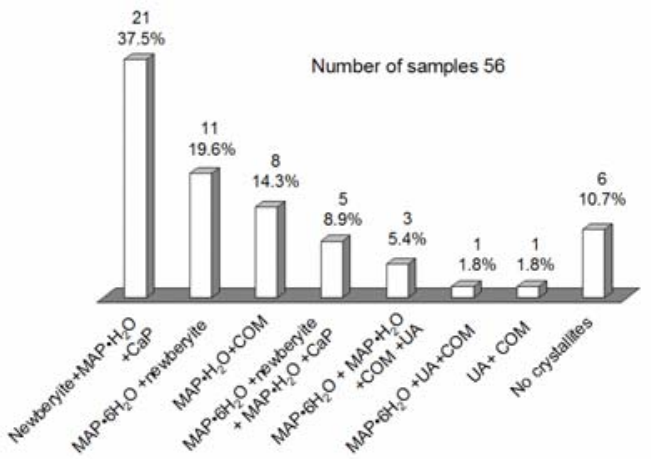

Figure 2. Components of urinary crystallites in 56 cases of MAP stone patients.

2) HRTEM and FFT analysis of urinary nanocrystallites

Fig. 4 shows the images obtained from HRTEM and FFT in different areas of the urinary nanocrystallites. We detected the spacing of lattice fringe at $d=4.71 \AA$, which was assigned to (110) plane of $\mathrm{MAP} \cdot \mathrm{H}_{2} \mathrm{O}$ in Figs. $4 \mathrm{a}$ and 4b. In Figs. 4c and 4d we also detected the lattice fringes at $\mathrm{d}=4.49 \AA$, which were assigned to (102) plane of $\mathrm{MgHPO}_{4} \cdot 3 \mathrm{H}_{2} \mathrm{O}$. In the Figs. $4 \mathrm{e}$ and $4 \mathrm{f}$, the lattices planes at $\mathrm{d}=2.96$ and 2.60 , which were assigned to $(\overline{2} 02)$ plane of COM and (220) plane of CaP, respectively.

Therefore, the main components of urinary nanocrystallites found in patients with MAP stones were $\mathrm{MAP} \cdot \mathrm{H}_{2} \mathrm{O}, \mathrm{MgHPO}_{4} \cdot 3 \mathrm{H}_{2} \mathrm{O}, \mathrm{COM}$ and $\mathrm{CaP}$, which is consistent with the result obtained from the XRD.

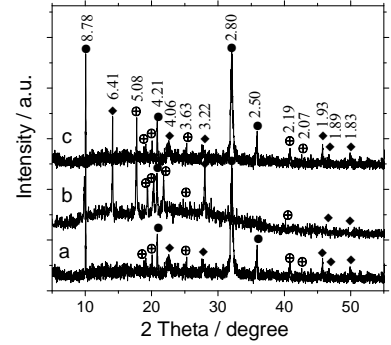

Figure 3. XRD spectra of three representative urinary nanocrystallites in patients with MAP stones. (a), (b), (c) correspond to the urinary crystallites of patient A, B, C, respectively. Symbols: $\bigcirc$ : MAP. $6 \mathrm{H}_{2} \mathrm{O}, \oplus$ : $\mathrm{MgHPO}_{4} \cdot 3 \mathrm{H}_{2} \mathrm{O} ; \mathbf{O}: \mathrm{MAP} \cdot \mathrm{H}_{2} \mathrm{O} ; \bullet: \mathrm{Ca}_{3}\left(\mathrm{PO}_{4}\right)_{2}$

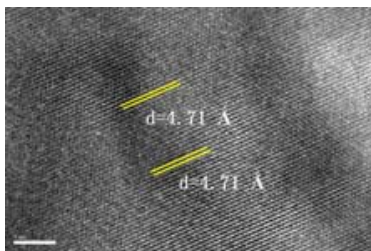

(a)

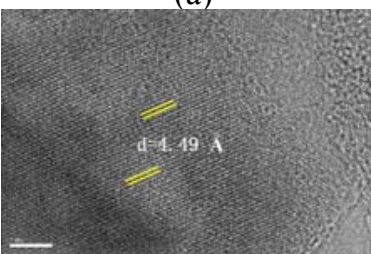

(c)

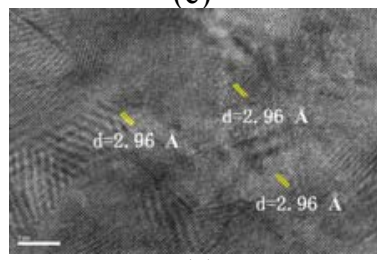

(e)

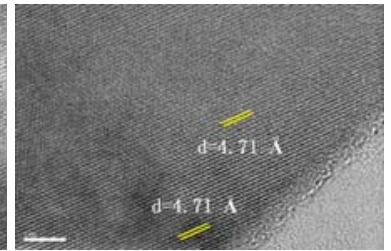

(b)

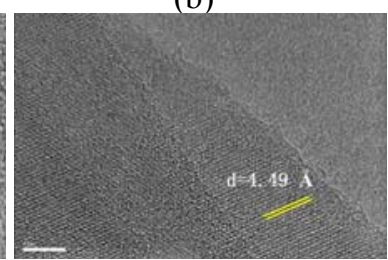

(d)

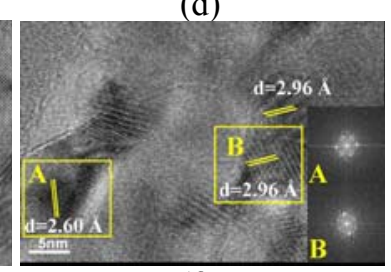

(f)
Figure 4. FFT images of HRTEM of urinary naocrystallites in MAP stone patients.

\section{DISCUSSION}

The main components of MAP stones were MAP $\cdot 6 \mathrm{H}_{2} \mathrm{O}$ and small amounts of newberyite, COM, $\mathrm{CaP}$, and HAP (Fig. 1), whereas the main components of urinary crystallites in patients with MAP stones were newberyite, MAP monohydrate $\left(\mathrm{MAP} \cdot \mathrm{H}_{2} \mathrm{O}\right)$, and small amounts of MAP• $6 \mathrm{H}_{2} \mathrm{O}$, COM, and CaP (Table 1).

The incidence of infectious stones is accounted for $10 \%$ to $15 \%$ in urinary calculi [13], in which females are more affected than males. The most common alkaline stones are $\mathrm{MAP} \cdot 6 \mathrm{H}_{2} \mathrm{O}$ (struvite) and newberyite, as well as carbonate apatite, ammonium acid urate and HAP. MAP stones are usually caused by urinary infections produced by urease-producing bacteria, and the most common pathogen is Proteus mirabilis. Urease, produced by a pathogen, hydrolyzes urea to form ammonium and increases ammonium 
concentration; as a result, urine becomes alkaline [14]. As MAP concentration reaches oversaturation, crystals are precipitated. Infections cannot be eradicated because MAP stone debris is difficult to remove during surgery. Therefore, stones grow rapidly and further impair kidney function after surgery; as such, the recurrence rate of MAP stones is higher than that of the other types of stones.

Lee [15] performed TGA and EDS to identify the components on the surface and interior layer of MAP calculi; results show that the components in the interior layer contain $64 \%$ MAP and $36 \%$ apatite, and the component on the surface is $\mathrm{CaOx}$. This result is observed because $\mathrm{PO}_{4}{ }^{3-}, \mathrm{CO}_{3}{ }^{2-}$, and $\mathrm{NH}^{4+}$ can combine with $\mathrm{Mg}^{2+}$ ions adsorbed on the biofilm surface of bacteria; struvite-calcium phosphate precipitates are then formed, thereby providing a nidus for crystal nucleation, growth, and aggregation. Furthermore, calcium phosphates can induce the development of $\mathrm{CaOx}$ crystals via heterogeneous nucleation [16]. In an in vitro experiment [17], carbonate apatite has precipitated from urine at $\mathrm{pH} 6.8$ whereas struvite has precipitated from urine at $\mathrm{pH}>7.2$.

In another study [18], the crystallization of $\mathrm{MgHPO}_{4} \cdot 3 \mathrm{H}_{2} \mathrm{O}$ as the first phase in human stone formation unlikely occurs. This process often accompanies or follows the precipitation of MAP• $6 \mathrm{H}_{2} \mathrm{O}$ and is randomly distributed among MAP stones. Therefore, MAP $\cdot 6 \mathrm{H}_{2} \mathrm{O}$ can be easily detected in stones; newberyite can also be easily observed in urinary crystallites. In another in vitro experiment [14], an MAP $\cdot \mathrm{H}_{2} \mathrm{O}$ seed crystal is used as a crystal growth template in a mixed solution. This solution contains urea and the bacterium Proteus mirabilis. Porous quasispherical particles of $\mathrm{MAP} \cdot 6 \mathrm{H}_{2} \mathrm{O}$ with diameters ranging from $3 \mu \mathrm{m}$ to $6 \mu \mathrm{m}$ are produced after $3 \mathrm{~d}$ of reaction. $\mathrm{MAP} \cdot \mathrm{H}_{2} \mathrm{O}$ induces the formation of MAP• $6 \mathrm{H}_{2} \mathrm{O}$ stones (struvite) as seed crystals. This process is fast but provides difficulty in detecting $\mathrm{MAP} \cdot \mathrm{H}_{2} \mathrm{O}$ when conventional methods are used. Hence, $\mathrm{MAP} \cdot \mathrm{H}_{2} \mathrm{O}$ was not detected in the stones in this study. However, a large amount of $\mathrm{MAP} \cdot \mathrm{H}_{2} \mathrm{O}$ was detected in urinary nanocrystallites.

\section{CONCLUSION}

XRD, FT-IR, and FFT of HRTEM were performed to study the components of urinary crystallites in 56 cases of patients with MAP stones. The main components of urinary crystallites in patients with MAP stones were newberyite, MAP monohydrate $\left(\mathrm{MAP} \cdot \mathrm{H}_{2} \mathrm{O}\right)$, and small amounts of MAP• $6 \mathrm{H}_{2} \mathrm{O}, \mathrm{COM}$, and $\mathrm{CaP}$, whereas the main components of MAP stones were $\mathrm{MAP} \cdot 6 \mathrm{H}_{2} \mathrm{O}$ and small amounts of newberyite, $\mathrm{COM}, \mathrm{CaP}$, and HAP. The results showed that the formation of MAP stones was closely related to the components of urinary crystallites. Therefore, crystallite components should be detected to help predict the formation of renal stones and different types of stones.

\section{ACKNOWLEDGMENTS}

This research work was granted by the Natural Science Foundation of China (81170649).

\section{REFERENCES}

[1] F. Grases, A. Llobera. "Experimental model to study sedimentary kidney stones," Micron, 1998, 29: 105-111.

[2] H. Peng, J. M. Ouyang, X. Q. Yao, R. E. Yang. "Interaction between sub-micron COD crystals and African green monkey renal epithelial cell,” Int. J. Nanomed., 2012, 7(8): 4727-4737.

[3] S. Zhang, Z. X. Su, X. Q. Yao, H. Peng, S. P. Deng, J. M. Ouyang. "Mediation of calcium oxalate crystal growth on human kidney epithelial cells with different degrees of injury," Mater. Sci. Eng. C-Mater. Biol. Appl., 2012, 32: 840-847.

[4] S. Zhang, H. Peng, X. Q. Yao, Z. X. Su, Z. Y. Xia, J. M. Ouyang. "Promotion on nucleation and aggregation of calcium oxalate crystals by injured African green monkey renal epithelial cells,' Chin. J. Chem., 2012, 30(3), 496-500.

[5] C. Y. Duan, Z. Y. Xia, G. N. Zhang, B. S. Gui, J. F. Xue, J. M Ouyang. "Changes in urinary nanocrystallites in calcium oxalate stone formers before and after potassium citrate intake," Int. J. Nanomed., 2013, 8: 909-918.

[6] G. N. Zhang, J. M. Ouyang, J. F. Xue, Y. F. Shang. "Property changes of urinary nanocrystallites and urine of uric acid stone formers after taking potassium citrate," Mater. Sci. Eng. C-Mater. Biol. Appl., 2013, 33: 4039-4045.

[7] M. Daudon, C. Hennequin, G. Boujelben, B. Lacour, P. Jungers. "Serial crystalluria determination and the risk of recurrence in calcium stone formers," Kidney Int., 2005, 67: 1934-1943.

[8] K. S. Le Corre, E. Valsami-Jones, P. Hobbs, S. A. Parsons "Impact of calcium on struvite crystal size, shape and purity," J. Cryst. Growth, 2005, 283(3-4): 514-522.

[9] M. King, W. F. McClure, L. C. Andrews, and M. A. Holomery 1992 Powder Diffraction File Alphabetical Index, Inorganic Phases/Organic Phases. International Center for Diffraction Data: 1601 Park Lane, Pennsylvania, 19081-2389, U.S.A.

[10] P. T. Bhatt, P. Paul. "Analysis of urinary stone constituents using powder X-ray diffraction and FT-IR," J. Chem. Sci., 2008, 120(2): 267-273.

[11] L. Benramdane, M. Bouatia, M. O. B. Idrissi, M. Draoui. "Infrared analysis of urinary stones, using a single reflection accessory and a KBr pellet transmission," Spectros. Lett., 2008, 41(2): 72-80.

[12] M. Daudon, C. Marfisi, B. Lacour, C. Bader. "Investigation of urinary crystals by Fourier transform infrared microscopy," Clin. Chem., 1991, 37(1): 83-87.

[13] C. A. A. Ghumman, O. M. T. Carreira, A. M. C. Moutinho, A Tolstogouzov, V. Vassilenko, O. M. N. D. Teodoro. "Identification of human calculi with time-of-flight secondary ion mass spectrometry," Rapid Commun. Mass Spectrom., 2010, 24(2): 185190.

[14] L. Chen, Y. H. Shen, A. J. Xie, F. Z. Huang, W. Q. Zhang, S. X Liu. "Seed-mediated synthesis of unusual struvite hierarchical superstructures using bacterium," J. Cryst. Growth, 2010, 10(5): 2073-2082.

[15] H. P. Lee, D. Leong, C. T. Heng. "Characterization of kidney stones using thermogravimetric analysis with electron dispersive spectroscopy,"Urol. Res., 2012, 40(3):197-204.

[16] F. Grases, A. Costa-Bauza, M. Ramis, V. Montesinos, A. Cont. "Simple classification of renal calculi closely related to their micromorphology and etiology," Clin. Chim. Acta., 2002, 322: 2936.

[17] P. Jolanta, T. Agnieszka. "Effect of curcumin against proteus mirabilis during crystallization of struvite from artificial urine,' ECAM(Evidence-Based Complementary and Alternative Medicine), 2012, 2012: 1-7.

[18] R. Boistelle, F. Abbona, H. E. Lundager Madsen. "On the transformation of struvite into newberyite in aqueous systems," Phys Chem Minerals, 1983, 9: 216-222. 